O filme-performance e o espaço qualquer: reflexões sobre a imagem-afecção em uma biografia audiovisual dançante

\title{
Cristiane Wosniak
}

Universidade Estadual do Paraná, Centro de Artes, Curitiba, Paraná, Brasil. Contato com a autora: cristiane.wosniak@ unespar.edu.br 
Resumo: Este artigo se propõe a analisar o filme-performance Buracos no Céu (Evaldo Mocarzel, 2013) e refletir sobre a construção do conceito de espaço qualquer, desenvolvido por Gilles Deleuze em sua ontologia da imagem cinematográfica. Minha análise se debruça, especificamente, sobre excertos do filme-performance, em que a imagem-afeccão, em seus lampejos icônicos da imagem-movimento, coteja os opsignos e sonsignos puros da imagem-tempo na construção de um modo documental performático. Como aportes para a reflexão pretendida também são consideradas algumas contribuições da semiótica peirceana, bem como outras teorias propostas por pesquisadores do cinema documental e das mídias audiovisuais.

Palavras-chave: Imagem. Comunicação. Filme-performance. Espaço qualquer. Dança.

Abstract: This article aims to analyze the performance-movie Holes in the Sky (Evaldo Mocarzel, 2013) and reflect on the construction of the concept of whatever space, developed by Gilles Deleuze in his ontology of the cinematographic image. The analysis is focused specifically on excerpts from performance-movie, in which the affection-image, in its iconic flashes of movement-image, matches the pure op-signs and son-signs of the time-image in the making of a performative documentary mode. As subsidies to the intended reflection, one also takes into account some contributions from Peirce's semiotics, as well as a few theories proposed by other researchers on documentary film and audiovisual media.

Keywords: Image. Communication. Performance-movie. Any-space-whatever. Dance. 


\section{Introdução}

Como toda a forma de arte, o cinema documental tem(é) um pensamento e tem(é) uma voz. Esse pensamento e essa voz se fazem presentes no ato fílmico per se, de maneiras diferenciadas, quando o sujeito-da-câmera estabelece asserções sobre o mundo, ou sobre alguém, ocorrendo, neste momento, uma espécie de indexação da obra.

A concepção de sujeito-da-câmera que adoto nesta análise é a proposta por Fernão Ramos (2008), ao afirmar que não se trata apenas do diretor, montador, ou operador de câmera, mas também da "subjetividade que é fundada pelo espectador na tomada [...]. O sujeito-da-câmera cobre como uma manta de presença a ação na tomada [...], é o conjunto da equipe que está atrás da câmera no momento da tomada" (RAMOS, 2008, p. 82-83).

Pergunto-me: qual seria a intenção do sujeito-da-câmera e, especificamente, do cineasta Evaldo Mocarzel ${ }^{1}$ ao realizar um filme-performance?

De acordo com Mocarzel (2013, p. 1), sua intenção seria "concretizar uma homenagem à personagem biografada, a artista da dança, Célia Gouvêa" ${ }^{2}$. Essa primeira voz documental - intencionalidade - ao escrever/elaborar a Carta de Montagem, ${ }^{3}$ que endereça à cineasta/ montadora Guta Pacheco, comunica qual é o seu ponto de vista social e como esse ponto de vista se cristaliza em suas opções estilísticas e modais. Quando o diretor se utiliza dessa voz panegírica, ele o faz por intermédio de todos os meios e procedimentos disponíveis à narrativa documentária.

Em Buracos no Céu ${ }^{4}$, Mocarzel (2013) se apropria da copresença da voz dançante evocada em depoimentos memoriais corporalizados em blocos distintos de lembranças da atriz social - e de imagens capturadas em tempos diversos (cenas noturnas e diurnas) de encenação em uma determinada locação: o telhado da Assembleia Legislativa do Estado de São Paulo, no Parque Ibirapuera.

A possível copresença a que me refiro é evidenciada por Jean-Louis Comolli em seu ensaio intitulado "Sob o risco do real" (2008), que explora a copresença do corpo no ato da filmagem como uma "potência de convicção, uma beleza que o corpo não filmado não conhece" (COMOLLI, 2008, p. 176). Copresença esta gerada pelo corpo inserido em lugares/locus

$1 \quad$ Evaldo Mocarzel nasceu em 1960 em Niterói, Rio de Janeiro. Formou-se em Cinema na Universidade Federal Fluminense e trabalhou como jornalista/editor do Caderno 2, do jornal O Estado de São Paulo, durante oito anos. Cursou Cinema na New York Film Academy e fez parte do Círculo de Dramaturgia do diretor Antunes Filho, no Centro de Pesquisa Teatral (CPT-SESC-SP). Em sua filmografia constam curtas e longas-metragens com ênfase em cinema documental.

2 Célia Gouvêa nasceu em 1949, na cidade de Campinas, São Paulo e é um dos grandes nomes da dança paulista. Atuou como bailarina, coreógrafa e professora de dança, fazendo carreira internacional.

3 Esta Carta de Montagem foi escrita pelo diretor e encaminhada à cineasta Guta Pacheco, em sua versão final, em 28 de maio de 2013. O documento, com cinco páginas, não foi publicado. Uma versão da Carta me foi cedida, em correspondência eletrônica, para uso neste trabalho.

4 Buracos no Céu é um documentário/curta-metragem produzido pela Casa Azul, com duração de 20 minutos. Tem a direção de Evaldo Mocarzel e montagem de Guta Pacheco. A fotografia é de Cleisson Vidal, e a direção de produção é de Letícia Santos. 
unicamente possíveis em virtude do processo de montagem cinematográfica.

Nos blocos do filme-performance, cuja duração é de vinte minutos, ocorre uma ênfase metafórica de planos-detalhes das mãos da artista da dança que traçam ícones cinéticos em direção ao céu. Gouvêa performa movimentos verticalizados, geográfica e cinematograficamente, ao som de estruturas sonoras diversas, aparecendo e desaparecendo entre cartelas escuras com títulos sugestivos, tais como: corpo, memória da pele, memória dos ossos, músculos, nervos e tendões, palimpsestos de lembranças, gestos e sensações. São em número de sete as personalidades evocadas ou emuladas pela artista da dança, na seguinte ordem de aparição na tela: Maurice Béjart (bailarino e coreógrafo), Ruth Rachou (coreógrafa), Maurice Vaneau (diretor teatral/parceiro), Odete Gouvêa (professora de piano/mãe), Vânia Vaneau (filha), Alwin Nikolais (coreógrafo) e René Gumiel (bailarina e coreógrafa).

O uso intensivo do procedimento de falso-raccord ${ }^{5}$ e o movimento do corpo da artista deflagrando os cortes cinematográficos em uma espécie de montagem-miríade permitem uma reflexão sobre as condições estéticas propostas pelo conceito de espaço qualquer (DELEUZE, 2009), ao se verificar sua potência em devir no objeto empírico de minha análise.

Por meio da análise fílmica, a hipótese a ser verificada é a possível confluência da imagem-afecção - imagem-movimento - em diálogo com os opsignos e sonsignos - imagem-tempo - presentes na narrativa.

Nesta perspectiva analítica, as mãos da artista da dança, ao performarem ícones cinéticos como recurso memorial/narrativo, tornar-se-iam o elo/elemento conectivo entre a copresença do corpo e da câmera na configuração coreográfica-cinematográfica documental do espaço qualquer, evidenciando modos diversos de leitura ou produção de sentido.

\section{O filme-performance: afetos e subjetividades do(no) espaço-tempo memo- rial}

O corpus da presente análise apresenta uma clara matriz performática que induz ao argumento deste trabalho: trata-se de um processo de criação conjunta. A bailarina e coreógrafa Célia Gouvêa, na qualidade de atriz-social, (per)forma uma espécie de dança memorial biográfica - matriz/modo performático do documentário - ante o dispositivo fílmico mocarzeliano, potencializado pelo uso de elementos cinematográficos tais como falsos-raccords, planos e contraplanos que se sucedem de forma fragmentária e (des)linearizada no espaço-tempo de re(a)presentação.

O filme-performance desenha-se como um emaranhado de pensamentos e figuras/imagens que trazem uma nova relação entre o passado/memória e o presente/virtual. Nas palavras de John Rajchman (2013), “o objetivo já não é recuperar ou relembrar o passado em uma cons-

$5 \quad$ O falso raccord de movimento é uma mudança intencional de plano que foge da lógica da continuidade clássica. Este tipo de procedimento procura mostrar variados pontos de vista e perspectivas da imagem, ampliando o 'devir qualitativo' da narrativa. 
ciência, individual ou coletiva, que lhe teria sucedido, mas, ao contrário, evitar qualquer tipo de fechamento dentro da memória privada" (RAJCHMAN, 2013, p. 179-180). Desta forma, passado e presente são justapostos por operações de colisão espaço-temporais.

De acordo com Ramos (2008), se na narrativa ficcional frequentemente ocorre a utilização de atores que representam personagens fictícios, "a narrativa documentária prefere trabalhar os próprios corpos que encarnam as personalidades no mundo, ou utiliza-se de pessoas que experimentam de modo próximo o universo mostrado" (RAMOS, 2008, p. 26). Em uma analogia à assertiva de Ramos, parece-me que a bailarina e coreógrafa biografada (re)conhece com(no) seu corpo e, especificamente, com o gesto performático reiterado de suas mãos alegóricas e dançantes, o universo memorial e afetivo a ser mostrado no filme.

Quando encena uma memória com as mãos rumo ao céu - imagens capturadas e montadas em variados planos-detalhe -, a artista da dança acaba por formalizar um jogo especular em que a sua voz fisicalizada re(a)presenta a si mesma, enquanto discursa ideologicamente sobre fatos históricos, memoriais e afetivos sobre si e sobre o(s) outro(s) que também conviveram e travaram relações sociais e artísticas consigo.

Bill Nichols (2005), em seu texto, "A voz do documentário" (2005), atesta a existência de, no mínimo, quatro estilos históricos de documentário, com características formais muito bem delimitadas e que mudam suas estratégias e vozes discursivas de acordo com as ideologias narrativas historicamente marcadas/datadas. Conforme Nichols (2012), é a voz fílmica que funciona como uma espécie de impressão digital, muitas vezes identificando a assinatura de um cineasta/diretor. $\mathrm{O}$ autor também identifica seis modos de representação documental, das quais uma delas é o modo performático.

Em Buracos no Céu, é possível reconhecer que há um afastamento criterioso do caráter objetivo e factual do depoimento em favor de uma performance sensível. Nesse tipo de filme, a ênfase recai sobre os aspectos subjetivos da memória, dos afetos, da experiência vivida: "os aspectos reais são amplificados pelos imaginários" (NICHOLS, 2012, p. 170). As metáforas são recorrentes e as licenças poéticas substituem gradativamente a representação realista do mundo histórico. São as características da expressividade pessoal que atestam ou re(a)presentam o indivíduo documentado como sujeito específico e emotivo. Desta forma, "esses filmes nos envolvem menos com ordens ou imperativos retóricos do que com uma sensação relacionada com sua nítida sensibilidade. A sensibilidade do cineasta busca estimular a nossa [...] por intermédio da carga afetiva aplicada ao filme" (NICHOLS, 2012, p. 171).

$\mathrm{Na}$ abertura do filme-performance [minutagem: 00:00:26 a 00:00:55], imagens das mãos da artista, em plano-detalhe e em contre-plongée - posição/angulação de câmera situada abaixo da linha dos olhos do personagem e voltada para cima - sucedem-se rapidamente, e são esses gestos manuais que deflagram os cortes cinematográficos em camadas metafóricas palimpsésticas propostas pelo procedimento de falso-raccord.

As mãos, como ícones cinéticos (figura 1), enfatizam, nesses momentos de ritmo inten- 
so da montagem- $c u t^{6}$, o discurso poético e subjetivo em detrimento da evidência documental referencial.

Figura 1 - Sequência de planos-detalhe das mãos da artista Célia Gouvêa: discurso performático
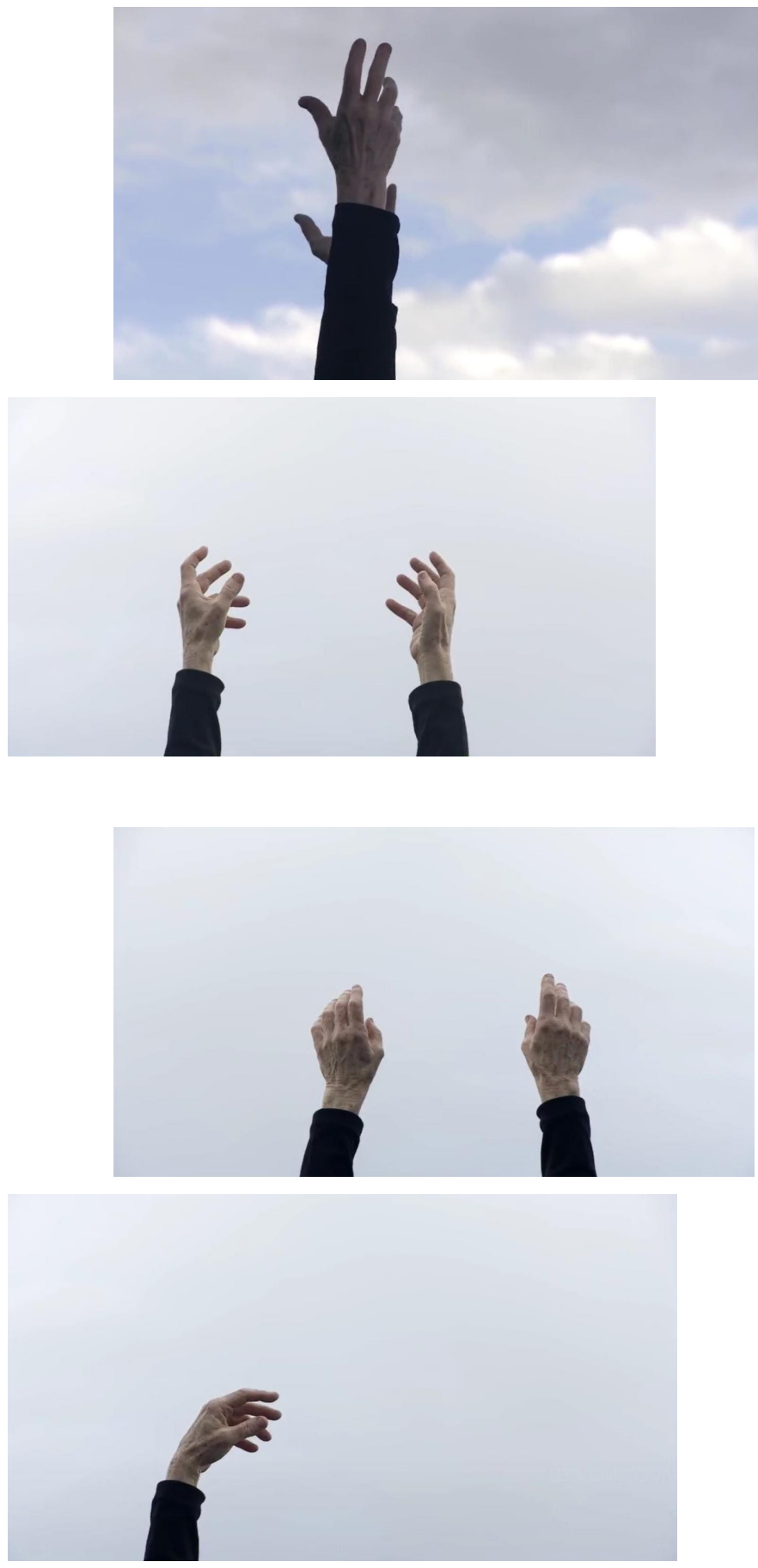

Fonte: frame de Buracos no Céu (Evaldo Mocarzel, 2013 - minutagem: 00:00:26 a 00:00:37)

Após a rápida sucessão de olhares/perspectivas sobre as mãos nuas a toma o espaço da

$6 \quad$ A montagem-cut refere-se ao corte seco na passagem de um plano a outro por uma simples colagem, sem que o raccord seja marcado por um efeito de ritmo ou truques estruturais. O objetivo é evitar encadeamentos lógicos e efeitos de transparência na narrativa. 
tela, tendo por fundo o azul claro do céu preenchido por nuvens passageiras, ocorre um longo período de contemplação de uma tonalidade azulada do céu sem o aparato das mãos em primeiro plano. Em seguida, a tela apresenta uma cartela preta com a seguinte citação: "as coreografias de Maurice Béjart ${ }^{7}$ são como buracos no céu [Fons Goris, professor de Jogo teatral de Célia Gouvêa na companhia Mudra]" (BURACOS NO CÉU, 2013).

O traço poético e sugestivo presente no excerto de abertura, ao som de uma melodia lenta tocada ao piano, revela o caráter paradoxal do documentário em seus tensionamentos entre a performance e o aspecto documental/factual.

Em Performing Documentary, Nichols (1994) esclarece que o documentário performático é híbrido e paradoxal, ao mesmo tempo, e "as qualidades expositivas podem falar menos sobre o mundo histórico do que servir para evocar ou engajar poeticamente este mundo. As questões de autoridade podem diminuir em favor de questões de tom, estilo e voz" (NICHOLS, 1994, p. 95, tradução nossa). É importante destacar que para Nichols o documentário performativo não esconde seus significados abertos e dialógicos sob o jugo de um referente.

Dessa forma, o documentário performático nos reorienta em direção ao mundo poético e histórico que traz significados rizomáticos e em devir para a existência. Essa mudança, segundo Nichols (1994), é paralela às noções da semiótica de Charles Sanders Peirce que dão prioridade à qualidade experiencial, fenomenológica, da relação de um indivíduo com os signos. $\mathrm{O}$ que Peirce chama de interpretante lógico poderia corresponder à tendência do documentário performático para nos dispor a rever a nossa relação com o mundo das evidências referenciais concretas.

Essa é a instância subjetiva e potente do modo performático que convoca o leitor/espectador a adentrar os recônditos de uma dança memorial/biográfica improvisada e, sinestesicamente, absorver as informações documentais rizomáticas: o filme configura-se como um documentário sobre a história afetiva da atriz social que vive(u) em meio à dança.

Nas palavras de Mocarzel, o seu filme-performance consiste em:

[...] uma montagem de planos-detalhe das mãos de Célia Gouvêa dançando as lindas e diferentes coreografias que ela criou e improvisou com o tema 'acenar'. Esse filme-performance é uma profusão de acenos, acenos de mãos que vão ao céu e voltam ao corpo para resgatar uma memória gestual que ficou decantada na memória da pele dessa grande bailarina e coreógrafa, uma artista maravilhosa, incansável, artista da cena, genuína, lúdica e sem medo dos deslumbrantes abismos da criação artística. De certa forma, 'Buracos no Céu' é um documentário sobre essas paisagens interiores, paisagens coreográficas no fundo da alma de Célia Gouvêa, guiando os gestos mais involuntários do seu dia a dia e logicamente todo tipo de expressividade quando ela entra em cena (MOCARZEL, 2013, p. 4).

Ao utilizar-se da metáfora das mãos dançantes como a abrirem buracos no céu, a história corporalizada da artista reveste-se em seu puro estado processual/qualis peirceano ou puro

$7 \quad$ Maurice Béjart (1927-2007) foi um bailarino e coreógrafo francês. Criou, na década de oitenta, o Ballet do Século XX e, mais tarde, o Mudra - Centro Europeu de Aperfeiçoamento e de Pesquisa dos Intérpretes do Espetáculo. Célia Gouvêa integrou a primeira turma deste coletivo criado por Béjart. 
devir (des)localizado em um espaço qualquer.

Neste momento de minha análise, acredito ser necessária a elucidação de alguns aspectos referentes aos conceitos de espaço qualquer e imagem-afecção para compreendermos de que forma e com que meios Deleuze realiza em seus dois livros, Cinema 1: a imagem-movimento (2009), e Cinema 2: a imagem-tempo (2007), um ensaio crítico com uma extensiva classificação das imagens e dos signos, propondo a noção de cinema como uma forma de pensamento.

\section{A imagem-movimento deleuziana: a imagem-afecção e o espaço qualquer}

Após o excerto da abertura, o bloco fílmico subsequente [minutagem: 00:02:36 a 00:05:34] revela, ao som que mescla composições de Igor Stravinsky e Maurice Ravel, uma cartela escura com a inscrição "Maurice Béjart", e o que se observa a seguir é uma série sucessiva de movimentos executados com as mãos e também com o corpo todo de Gouvêa, sendo focalizado e recortado obsessivamente por meio de falsos-raccords, inseridos em uma mesma locação-encenada, cuja "tomada realizada explora a fundo a tensão entre a encenação e o mundo em seu cotidiano" (RAMOS, 2008, p. 42).

A encenação performática de Gouvêa varia alternadamente entre um fundo claro (filmagem diurna) e escuro (filmagem noturna), criando uma (a)temporalidade espacial narrativa por meio da montagem-cut.

A leitura da Carta de Montagem, redigida pelo diretor, revela-nos tratar-se de um espaço geográfico determinado: o telhado da Assembleia Legislativa do Estado de São Paulo, tendo ao fundo elementos culturais e naturais. O filme apresenta imagens do firmamento, das nuvens passageiras, do parque Ibirapuera com suas árvores, além de um chafariz que parece dançar um dueto com a performer, em alguns momentos, como em sua tentativa de verticalidades irmanadas rumo ao céu matutino e vespertino de um espaço alegórico.

Entretanto, o filme-performance mocarzeliano não se detém nas imagens em plano geral e médio do corpo da artista, contextualizando as coordenadas espaço-temporais de forma contínua e narrativa. O documentário explora, antes, o interstício imaginante e em devir, no qual o corpo físico possivelmente habita um diferente contexto espacial cinematográfico.

Imagens em close-up do rosto de Gouvêa (figura 2), assim como os variados planos-detalhes de suas mãos rumo ao céu infinito, abstraem as coordenadas espaço-temporais e irrompem em um espaço próprio cinematográfico que Deleuze descreve como o espaço qualquer.

Figura 2 - Variados close-ups (rostidade deleuziana) da artista Célia Gouvêa: imagem-afecção 

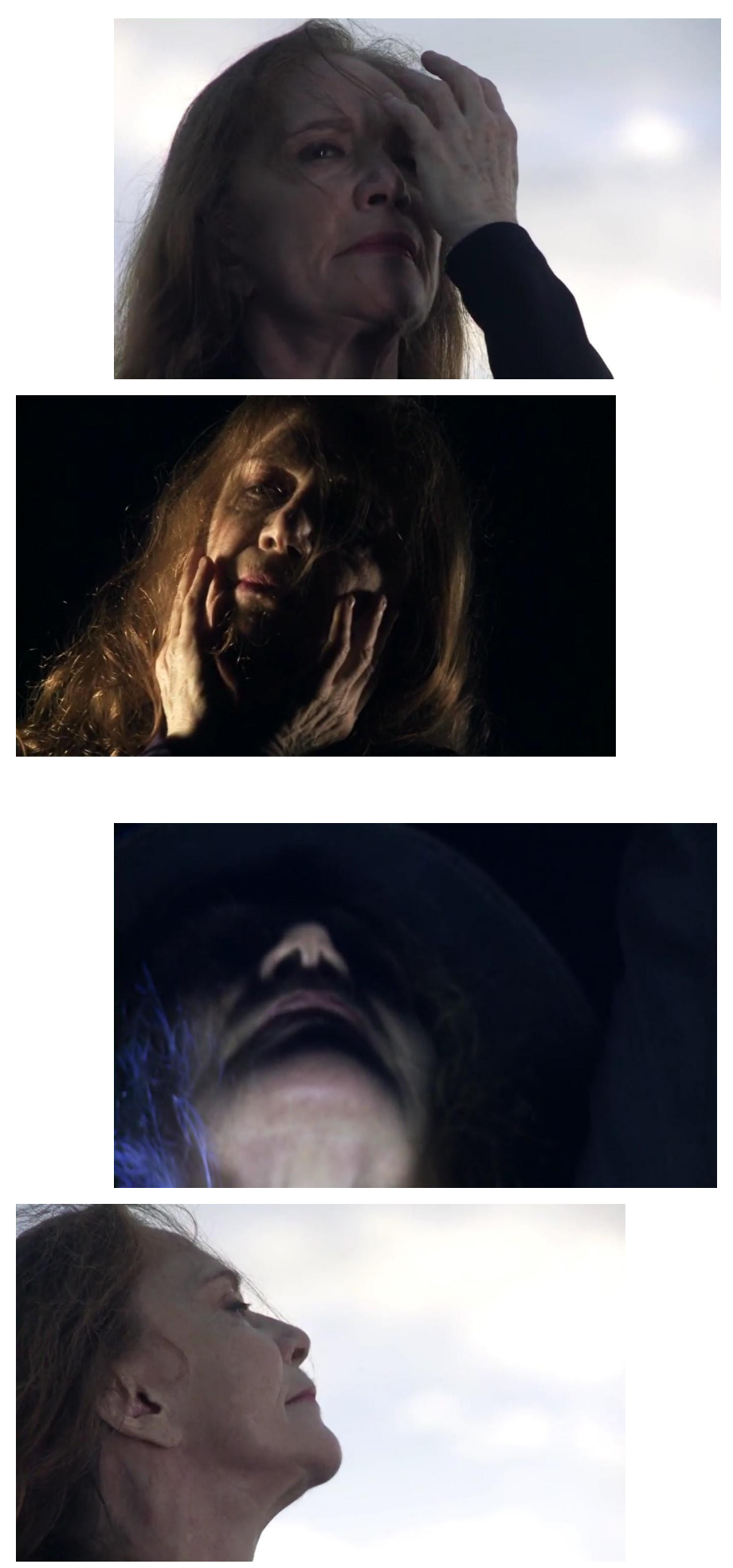

Fonte: frame de Buracos no Céu (Evaldo Mocarzel, 2013 - minutagem: 00:04:34 a 00:18:15)

E como Deleuze desenvolve o conceito de espaço qualquer em seu pensamento sobre o cinema?

Ao se apropriar dos signos da semiótica de Peirce, Deleuze os atualiza na construção de sua ontologia da imagem cinematográfica e propõe um cinema da diferença. Ao distinguir situações sensório-motoras de situações óticas (opsignos) e sonoras (sonsignos) puras, o filósofo francês transcende a classificação semiótica peirceana, criando uma nova categoria de signos 
oriundos de sua formulação da imagem-tempo. Deleuze(2009) esclarece que, na passagem/ruptura do esquema sensório-motor da imagem-movimento para a implicação em situações óticas e sonoras puras, da imagem-tempo, ocorre a necessidade de transcender e atualizar a semiótica peirceana - restrita e finita, segundo o filósofo francês, em sua terceiridade - o que o leva a criar uma nova categoria sígnica, pautada em termos como opsignos, sonsignos, mnemosignos, tactisignos, hialosignos, lektosignos, cronosignos e noosignos.

Trata-se de uma teoria fundamentada na relação que as imagens estabelecem entre si, a partir de perspectivas diferenciadas de encadeamento no espaço-tempo. Esta asserção é corroborada por teóricos como Jacques Rancière (2003), Raymond Bellour (2005) e Roberto Machado (2010), em seus amplos estudos acerca de Deleuze, a imagem e o cinema.

Antonio Fatorelli (2013), por sua vez, afirma que a imagem, em Deleuze, se apresenta como uma imagem fabricada "tomando por base os interstícios e os intervalos aplicados pelos centros de indeterminação, pela imagem-afecção, no caso da imagem-movimento, e pelas ações disjuntivas engendradas pelas situações ópticas e sonoras puras, no caso da imagem-tempo" (FATORELLI, 2013, p. 163).

Deleuze (2007) acredita que a imagem-movimento ocorre - ilusoriamente - nos intervalos dos fotogramas. Como agenciamento desse conceito, verifica-se a ênfase na montagem dos planos e nos movimentos da câmera. A partir dessa tipologia cinematográfica e em analogia direta à gramática especulativa da semiótica peirceana, o filósofo propõe três tipos de imagens concernentes à imagem-movimento: 1) imagem-relação [terceiridade peirceana); 2) imagem-ação [secundidade peirceana]; e 3) imagem-afecção [primeiridade peirceana].

A imagem-afecção, foco de meu interesse nesta análise, é caracterizada pela potência expressiva da primeiridade peirceana e com o caráter monádico do ícone.

Cumpre esclarecer que, para Peirce, "cada ícone participa de algum caráter mais ou menos aberto de seu objeto. Eles, um e todos, participam do caráter mais aberto de todas as mentiras e decepções: sua abertura" $(\mathrm{CP}, 4.531)^{8}$. Um ícone, portanto, não se reporta a nenhum objeto referencial, mas existe como qualidade, possibilidade e potência em devir.

No documentário memorial e afetivo, os ícones cinéticos traçados pelas mãos da artista em direção ao firmamento tornam-se frutos de um potencial qualitativo da mente, do pensamento, ao produzirem configurações originais, espontâneas, que não são copiadas de algo prévio. Tais traços icônicos, fragmentados e reinseridos no espaço qualquer pelo procedimento de montagem-cut em falso-raccord, brotam como frutos incontroláveis de associações, que não têm compromisso com o real, bastando ser uma mera possibilidade, um sentimento/feeling, uma forma.

A fisicalidade do corpo dançante se pronuncia como voz documental-performática na primeiridade, simplesmente como forma, lembrando que: "nenhum ícone puro representa nada

8 As citações da obra de Peirce seguem uma padronização $(\mathrm{CP})$ que fazem referência à edição Collected Papers of Charles Sanders Peirce, Harvard University Press, 1931-1958, 8 volumes. No código, a primeira cifra reporta-se ao volume, a segunda ao parágrafo. 
além de forma, nenhuma forma pura é representada por nada a não ser um ícone [...] os ícones nada podem representar além de formas e sentimentos" (CP, 4.544).

A imagem-afecção funciona como uma espécie de signo icônico no qual o afecto - aquilo que a imagem está apta a ser, sua inteligibilidade qualitativa, sem o acesso ao fora de campo contextual, qualis processual/feeling - constitui-se como possibilidade imanente e de frescor inusitado de um signo em sua primeiridade. Deleuze (2009) toma como exemplos cenas fílmicas em close-up às quais se refere como rostidade (figura 2).

Ao entender a primeiridade peirceana como a categoria do possível, exprimindo o possível sem o atualizar, fazendo dele um modo completo, ele estabelece uma relação direta com a imagem-afecção, afirmando que "a imagem-afecção é a qualidade ou o poder, é a potencialidade considerada por si mesma enquanto exprimida" (DELEUZE, 2009, p. 152).

É na relação da imagem-afecção como qualidade-poder que Deleuze (2009, p. 151) estabelece a indeterminação da imagem-afecção quanto à localização fixa espaço-temporal e determina que é o ícone "o signo da composição bipolar da imagem-afecção".

Deleuze prossegue em suas reflexões e assevera que esta instância é independente de todo o espaço-tempo determinado, que não comporta coordenadas espaço-temporais, objetos e pessoas, conexões concretas e reconhecíveis entre todos estes dados.

A imagem-afecção tem por signo de composição o 'ícone', que pode ser de qualidade ou de potência; é uma qualidade ou uma potência apenas expressas [...], sem serem atualizadas. Mas é o ‘qualissigno’ ou o ‘potissigno', que constitui o elemento genético, porque constroem a qualidade ou a potência num espaço qualquer, quer dizer, num espaço que ainda não aparece como meio real (DELEUZE, 2007, p. 48).

$\mathrm{Na}$ trilha da imagem-afecção, Deleuze estabelece o conceito de espaço qualquer, a partir de Pascal Auger ${ }^{9}$, como um espaço (des)coordenado em suas relações métricas e lógicas.

Em uma entrevista a Nicolas Rousseau, Auger (2011) declara que foi o inventor da palavra composta e que Deleuze desenvolveu esta expressão, posteriormente, aplicando-a à imagem-movimento. Deleuze (1982) confirma e credita a autoria da ideia de espaço qualquer ao seu aluno/cineasta no curso da Universidade de Vincennes e também menciona “Auger" em Cinema 1: imagem-movimento (2009, p. 169).

Auger ratifica que além do espaço qualquer ser um lugar, é uma maneira de filmar este lugar, ou seja: "o espaço qualquer não existe, é construído por meio da filmagem do lugar" (AUGER, 2011, s/p). Indo além deste raciocínio, Deleuze afiança que o espaço-qualquer,

não é um universal abstrato, em todo o tempo, em todo o lugar. É um espaço perfeitamente singular, só que perdeu sua homogeneidade, isto é o princípio de suas relações métricas ou a conexão das suas próprias partes, pelo que as ligações podem fazer-se de uma infinidade de maneiras. É um espaço de conjunção virtual, captado como puro

9 Pascal Auger - nascido em 1955, em Paris. Artista, cineasta e videomaker. Foi aluno de Gilles Deleuze na Universidade de Vincennes e depois em Paris VIII, em Saint-Denis (entre 1975-1987). Foi docente desta instituição (entre 1980-1982). Criou a expressão espaço-qualquer, desenvolvida por Deleuze em Imagem-movimento. Dedica-se ao cinema experimental e às audiovisualidades. 
lugar do possível (DELEUZE, 2009, p. 169).

Depreendemos, portanto, que o espaço qualquer é construído em ato cinematográfico como um espaço intersticial, tátil, atual e virtual, estado em puro devir e pleno de potencialidades de leitura.

A partir destas proposições deleuzianas, pergunto-me se é possível afirmar que o espaço qualquer presentificado em Buracos no Céu é descoordenado, desenquadrado, fragmentado e reinserido, por meio dos falsos-raccords, em blocos de espaço-tempo e efeitos da imagem-afecção. E o que, em termos deleuzianos, contribui para dar o tom afetivo ao filme-performance em questão?

Uma das possíveis respostas à indagação poderia se concentrar na afirmação de Deleuze (2009, p. 137) “a imagem-afecção é o grande-plano e o grande plano é o rosto.”

A focalização de planos-detalhes, tanto do rosto quanto das mãos da artista homenageada em Buracos no Céu, desarticulando os referenciais e as coordenadas espaço-temporais, abrem-se a incontáveis potências qualitativas ao longo do filme-performance (figura 3).

As mãos constituem-se em traços cinéticos icônicos, na expressão de Peirce e, ao mesmo tempo, por procedimentos cinematográficos, ao utilizar os close-ups e não mais os amplos planos de corpo inteiro dançante, a metonímia imagética deixa de ser "translação para se tornar expressão" (DELEUZE, 2009, p. 149).

Figura 3 - ângulos e planos sem coordenadas geográficas determinadas: o corpo no espaço qualquer
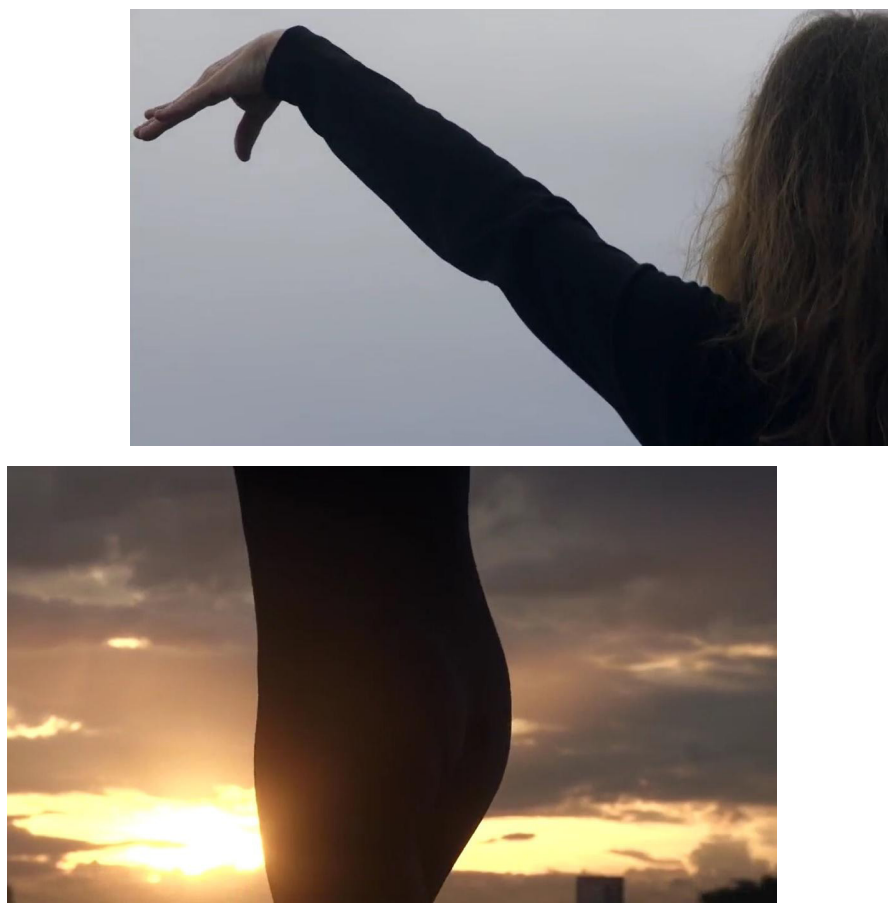

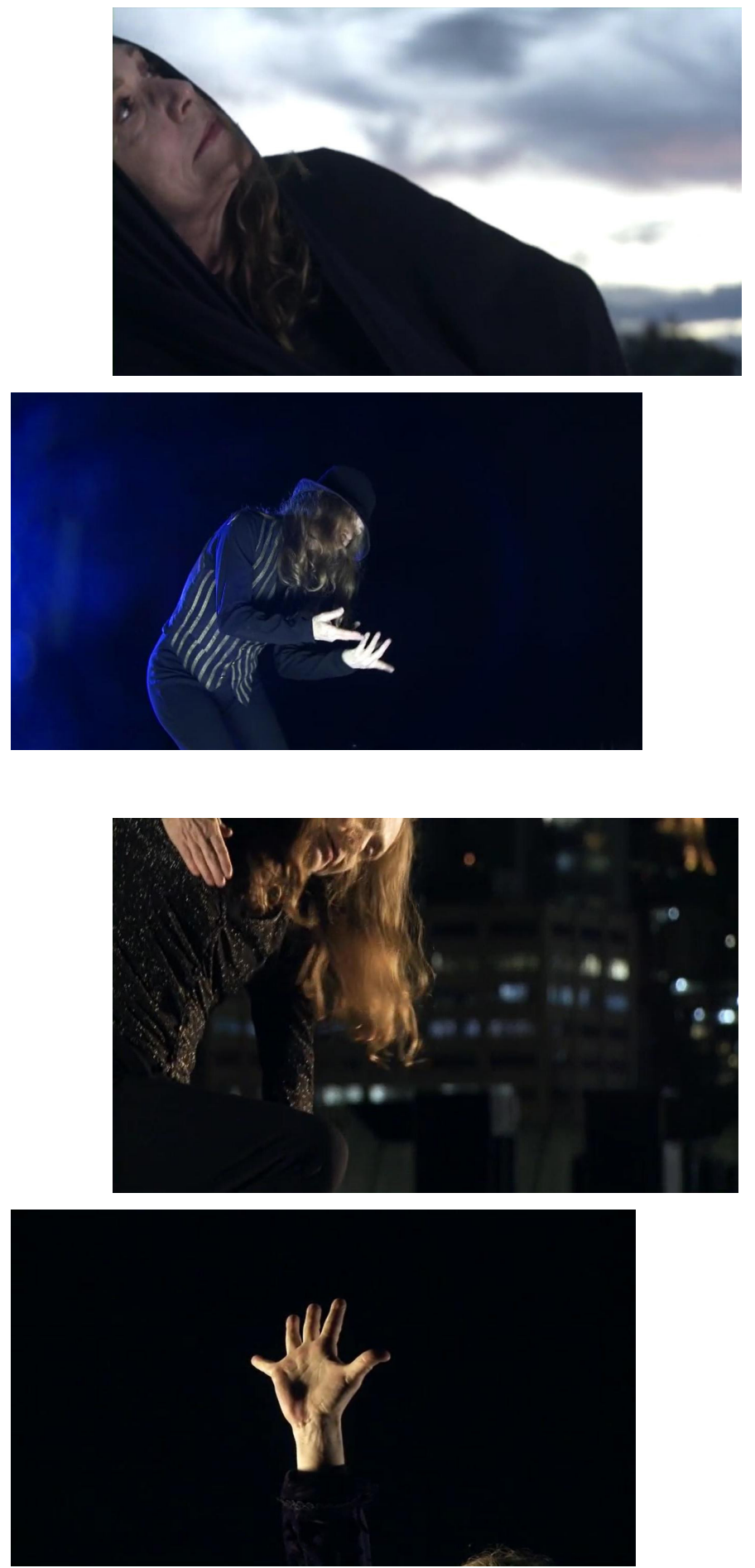

Fonte: frame de Buracos no Céu (Evaldo Mocarzel, 2013 - minutagem: 00:02:55 a 00:16:52)

Célia Gouvêa, nesta longa sequência de planos [minutagem 00:02:55 a 00:16:52], performa ante uma gama variada de fundos de tela: espaços figurativos, intersticiais e alegóricos como a simbolizar o grande palco da vida - e não necessariamente a cidade de São Paulo onde ocorre a tomada - repletos de luzes. Seus braços e suas mãos, como imagens-afecção, atravessam a tela e rasgam qualquer coordenada espacial definitiva. $\mathrm{O}$ espaço qualquer torna-se a celebração do falso-raccord como elo de ligação entre as imagens e os planos.

Afirma Deleuze(2009, p. 170) que “o espaço qualquer será o elemento genético da ima- 
gem-afecção". E, neste caso, o rosto e as mãos da artista prefiguram uma certa paisagem icônica (in)definida. Fragmentos do corpo tornam-se paisagens poéticas.

Leonardo Araújo Oliveira, em Filosofia e cinema em Deleuze: da imagem-movimento às condições de sua superação, aponta que, em Mil Platôs - portanto, anteriormente à sua versão de Cinema 1: a imagem-movimento -, Deleuze já pensava uma espécie de ontologia do rosto ou da rostidade no cinema: "o primeiro plano já enquadra os objetos rostificando-os. Algo é rostificado mesmo se não se assemelha a um rosto. O close seria o que define a natureza do rosto" (OLIVEIRA, 2011, p. 8).

Destarte, Oliveira (2011), interpreta que não apenas o rosto teria o estatuto da rostidade icônica da imagem-afecção deleuziana, mas este rosto não necessariamente deveria ser um rosto humano, mas qualquer objeto enquadrado em primeiríssimo plano.

A partir desta assertiva, em Deleuze e Guattari, encontro uma afirmação sobre a amplitude expressiva e significante do enquadramento do rosto em primeiro plano. Afirmam os autores que, "o close de cinema trata, antes de tudo, o rosto como uma paisagem" (DELEUZE; GUATTARI, 2010, p. 36).

A rostidade, então, amplificaria as possibilidades disruptivas de ligação entre os planos, as paisagens e as continuidades, tornando-se não apenas uma marcação, mas um conceito em devir acoplado ao espaço qualquer.

Nuno Carvalho reconhece que este princípio disruptivo de ligação entre as imagens desempenha uma função essencial neste tipo de espaço. Segundo o autor, o raccord "desfazendo-se das conexões legais, lógicas, e causais que submetem as ordens espaciais a uma ordem pré-determinada, [...] constrói e inventa espaço 'bocado por bocado"' (CARVALHO, 2014, p. 19).

E neste caso, não apenas o rosto, mas as mãos da artista tornam-se emblemas da rostidade deleuziana.

\section{0 filme-performance e a imagem-tempo: opsignos e sonsignos em coexis- tência}

Em um determinado excerto do filme-performance [minutagem: 00:10:47 a 00:15:38], surge uma cartela preta com a inscrição "Odete Gouvêa”, na qual, segundo Mocarzel "a artista homenageia sua mãe, a pianista Odete Gouvêa" (MOCARZEL, 2013, p. 4).

A partir deste plano, o que se descortina na tela é mais um desfile de imagens estilhaçadas e reagrupadas em falsos-raccords. A novidade é que Gouvêa, a partir do movimento contínuo - um giro sobre si mesma -, parece dedilhar um piano imaginário enquanto suas mãos, envoltas em luvas pretas e brancas, alternam-se sucessivamente, ao som de uma vibrante melodia tocada ao piano (figura 4).

Figura 4 - Sequência de planos em falso-raccord: luvas brancas e pretas como teclas de um piano 

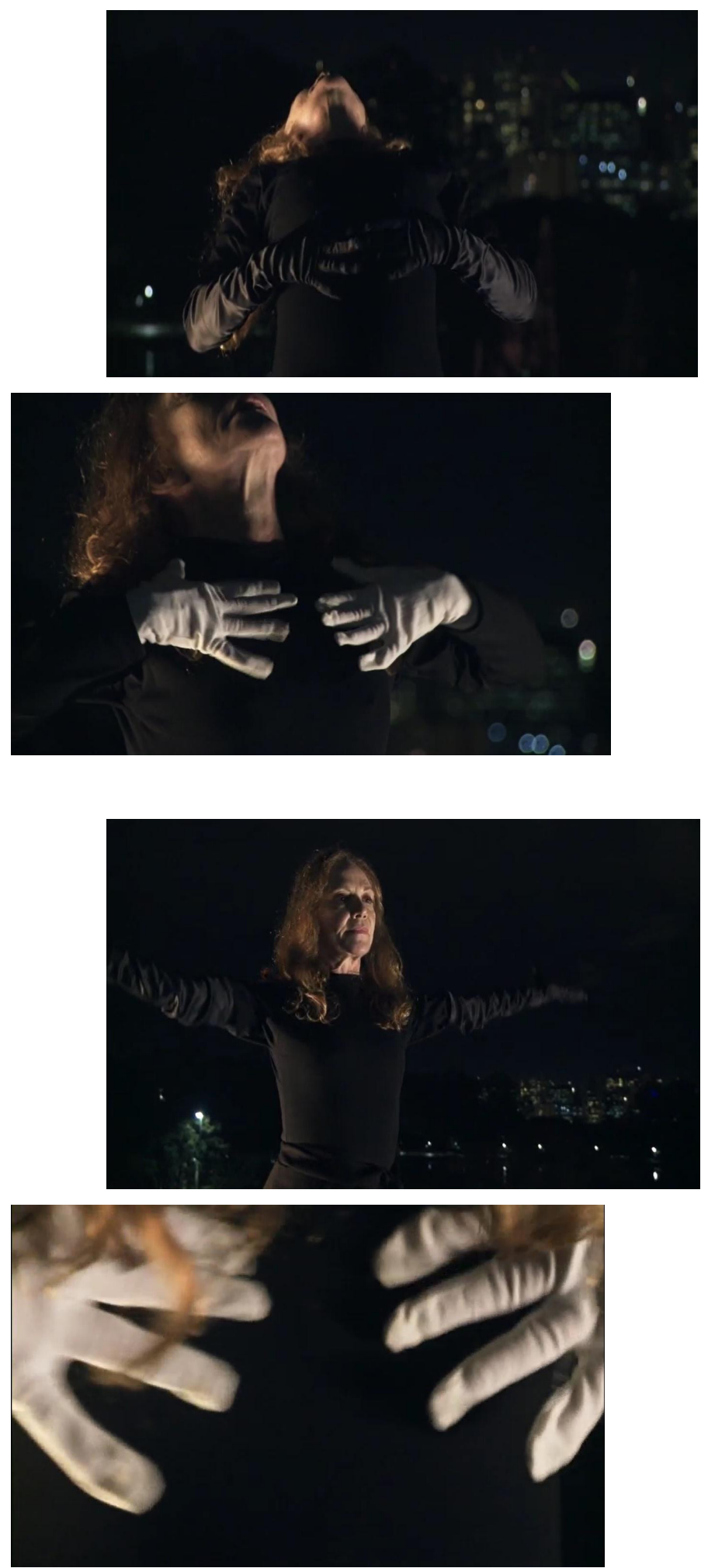

Fonte: frame de Buracos no Céu (Evaldo Mocarzel, 2013 - minutagem: 00:11:05 a 00:13:26)

O fundo da tela permite antever, por momentos, o firmamento em suas tonalidades noturnas, azuladas e negras repletas de luzes borradas. Desfile de imagens que se sucedem em cortes deflagrados pelos gestos na mesma intensidade rítmica da estrutura sonora. As mãos esboçam, nesta sequência de planos recortados, opsignos e sonsignos puros no espaço-tempo de re(a)presentação. 
Os movimentos de câmera enquadram a personagem sob variados ângulos e planos diversos: mãos que se direcionam ao céu, permitindo uma visualização do corpo em plano médio; um chafariz que se verticaliza em movimento dançante, parecendo acompanhar a trajetória das mãos na criação alegórica de buracos no céu; mãos que se direcionam à câmera e, em consequência, ao leitor/espectador; mãos que tocam partes do próprio corpo, como a fundamentar a tese de que a memória, o mnemosigno deleuzeano, habita a história e se reconecta audiovisualmente, por meio da imagem-cristal. Presente e passado não são emulados aqui por uma escala de sucessão, mas entram em colisão temporal coalescente, enquanto o espaço qualquer da imagem-afecção contamina os opsignos e sonsignos puros da imagem-cristal.

Ao simular com suas mãos envoltas em luvas brancas e pretas as teclas de um piano, em homenagem metafórica à sua mãe pianista, Gouvêa anuncia com seus gestos, deflagrando os cortes mocarzelianos, que o espaço-tempo de re(a)presentação não mais reflete cinematograficamente sobre sucessão, mas aponta para a coexistência em devir.

$\mathrm{E}$ de que forma e com que meios Deleuze inaugura seu raciocínio filosófico sobre a imagem-tempo?

Deleuze indaga e reflete sobre a filosofia de Henri Bergson e, especificamente sobre suas obras Matéria e Memória (2006) e A Evolução Criadora (2005), e, a partir da noção de tempo e duração em Bergson, embasa sua caracterização do cinema da diferença ou da imagem-tempo. Bergson (2006) alude à ideia de que o tempo deixa de ser apenas sucessão para se apresentar como coexistência. Surgem, em devir pleno, novas abordagens para uma temporalidade caracterizada, segundo Deleuze (2007), a partir da inauguração do cinema como uma forma de pensamento.

O esquema sensório-motor e as noções e reações de causa e efeito da imagem-movimento seriam rompidas para dar lugar a situações óticas e sonoras puras. Novas categorias imagéticas e sígnicas são instauradas a partir da superação da representação triádica da semiótica peirceana. Novas imagens decorrentes da imagem-tempo têm origem: 1) imagem-sonho (onirossignos); 2) imagem-lembrança (mnemossignos); 3) imagem-cristal.

As mãos dançantes de Gouvêa, ao rememorar/celebrar/homenagear sua mãe pianista, apresentam potenciais ou qualidades do presente - caráter atual no filme-performance - sem correlações ou determinações fixas. O passado/mnemosigno se atualiza constantemente, como em uma face especular na ação presentificada sem necessariamente, a intermediação entre o lembrado e o performado.

Pela definição de Bergson (2006), diferentes níveis de passados e memórias se entrecruzariam, por meio de circuitos temporais, de forma sincrônica até que se apresentassem estímulos do mundo/virtual que reconduzissem essas lembranças às suas atualizações. Esses circuitos (a)temporais de sonhos permitiriam tecer possíveis linhas de fuga para uma espacialização do tempo, devido às suas anamorfoses. Nesse tipo de imagem, os objetos e os meios adquirem a (in)consistência de uma (ir)realidade material autônoma, sem compromisso com um suposto real/referente. 
Para Deleuze (2007), os cortes (ir)racionais e estilhaçados são abundantes na imagem-cristal, pois a manifestação direta da imagem tempo encontra-se totalmente imersa no tempo e somente no tempo.

Nesse momento da reflexão, avento a seguinte possibilidade: o filme-performance Buracos no Céu preconiza uma suposta reversão da subordinação icônica-afectiva da imagem-movimento (co)relacionando o ícone cinético também aos opsignos e sonsignos, em sua potência qualitativa peirceana e em seu devir deleuzeano, num espaço qualquer?

Deleuze (2007), em sua concepção de opsignos e sonsignos puros, propõe uma hipótese: por meio da montagem - que, em seu entendimento, constitui o todo e nos dá uma imagem do tempo - seria possível ter acesso a imagens sonoras e óticas puras, isentas de qualquer referente fora delas mesmas.

E este não seria também o ideal do afecto icônico?

O argumento a ser explicitado na conclusão desta análise, portanto, é o de que as mãos dançantes de Célia Gouvêa, estruturando-se a partir da imagem-tempo deleuzeana e em específico, por meio dos mnemosignos/memórias [subdivisão estrutural da imagem-tempo], também se atualizam e se transformam, nesse percurso sígnico, em pura imagem-cristal, em uma celebração de imagens óticas e sonoras puras, porém levemente impregnadas, em algumas instâncias, do afecto icônico da imagem-afecção.

De que forma? Por estarem conjugadas e em esquema de colisão coalescente em um espaço qualquer desenhado pela montagem-cut e pelos procedimentos de falso-raccord propostos pelo cineasta Evaldo Mocarzel e levados a termo pela montadora Guta Pacheco.

Cabe mencionar que, para Deleuze (2009), existem dois tipos de signos de imagem-afecção: "por um lado a qualidade-poder exprimida por um rosto ou um equivalente [mãos]; mas, por outro lado, a qualidade-poder exposta num espaço qualquer" (DELEUZE, 2009, p. 170).

As qualidades memoriais evocadas no filme-performance têm uma voz que fala menos sobre o mundo histórico, mas engaja poeticamente este mundo ao estilhaçar uma lógica sequencial e inserir o corpo/as mãos da artista neste espaço qualquer, fruto do potencial cinematográfico.

\section{Considerações finais}

O objetivo desta reflexão, que tomou como objeto empírico de análise excertos do filme-performance Buracos no Céu de Evaldo Mocarzel, foi demonstrar como as memórias hápticas da artista Célia Gouvêa - homenageada pelo cineasta/diretor em uma biografia audiovisual dançante - se atualizam, por meio da imagem-afecção, ao inserir no espaço qualquer deleuziano os opsignos e sonsignos puros da imagem-cristal, fazendo colidir o atual e o virtual.

$\mathrm{O}$ argumento que percorreu a base desta reflexão analítica foi o fato de que as mãos da atriz-social se tornam um signo icônico cinético e conectivo do(no) espaço qualquer. 
A partir de uma narrativa memorial de si mesma, calcada na performance das mãos rostidade da artista - o diretor e cineasta Mocarzel procurou deflagrar os cortes cinematográficos em função dos gestos e, com este procedimento, acabou por estabelecer uma pequena via de acesso entre a imagem-afecção em sua potencialidade em devir e os opsignos e sonsignos, avizinhados perceptivamente por aquilo que Peirce concebe como ícone puro.

É possível relacionar o conceito de ícone puro à classe de qualissigno, que remonta às potencialidades em devir, ao interstício imaginante, ao sentimento/feeling da primeiridade

peirceana. É na vertente do imaginante e do possível que percebo o ícone cinético peirceano a contaminar, a partir do conceito deleuzeano de imagem-afecção, os próprios opsignos e os sonsignos da imagem-cristal.

E, assim sendo, é desta forma que posso deduzir que a imagem-tempo presentificada em Buracos no Céu ainda mantém latente, em sua borda esgarçada, lampejos luminosos do afecto icônico da imagem-movimento.

\section{Referências}

AUGER, Pascal. Em torno de Deleuze e do cinema. Entrevista concedida a Nicolas Rousseau. 11 de julho de 2011. Disponível em: <http:www.actu-philosophia.com/spip.php?article316>. Acesso em: 29 dez. 2017.

BELLOUR, Raymond. Pensar, contar: o cinema de Gilles Deleuze. In: RAMOS, Fernão Pessoa (Org.). Teoria contemporânea do cinema. v. 1. São Paulo: SENAC-SP, 2005. p. 233-252.

BERGSON, Henri. A evolução criadora. São Paulo: Martins Fontes, 2005.

BERGSON, Henri. Matéria e memória. São Paulo: Martins Fontes, 2006.

BURACOS no céu. Direção de Evaldo Mocarzel. Brasil - Casa Azul Produtora. 2013. 1 filme (20 min.): son.; color.; suporte DVD.

CARVALHO, Nuno. Deleuze: do spatium intensivo ao espaço qualquer. Kairos- Revista de Filosofia \& ciência, Lisboa, v. 11, 2014 (p. 91-115). Disponível em: <https://www.scribd. com/document/342235665/Kairos-11-Deleuze-Do-Spatium-Intensivo-Ao-Espaco-Qualquer>. Acesso em: 24 jan. 2018.

COMOLLI, Jean-Louis. Sob o risco do real. In: COMOLLI, Jean-Louis (Org). Ver e poder - a inocência perdida: cinema, televisão, ficção, documentário. Belo Horizonte: Editora UFMG, 2008, p. 169-178.

DELEUZE, Gilles. Cinema Cours. Paris VIII, 11, mar. 1982. In: La voix de Gilles Deleuze en Ligne (L'Association Siècle Deleuzean). Disponível em: <http://www2.univ-paris8.fr/deleuze/ article.php3?id_article=174>. Acesso em: 29 dez. 2017.

DELEUZE, Gilles. Cinema 2: a imagem-tempo. São Paulo: Brasiliense, 2007.

DELEUZE, Gilles. Cinema 1: a imagem-movimento. São Paulo: Brasiliense, 2009. 
DELEUZE, Gilles; GUATTARI, Felix. Mil Platôs: capitalismo e esquizofrenia. São Paulo: Editora 34, 2010.

FATORELLI, Antônio. Imagem e afecção nas novas mídias. In: PARENTE, André (Org.). Cinema/Deleuze. Campinas, SP: Papirus, 2013.

MACHADO, Roberto. Deleuze e o cinema. In: MACHADO, Roberto (Org). Deleuze, a arte e a filosofia. Rio de Janeiro: Jorge Zahar, 2010, p. 245-296.

MOCARZEL, Evaldo. Carta de montagem endereçada a Guta Pacheco. São Paulo, 28 de maio, 2013 [não publicada].

NICHOLS, Bill. Performing documentary. In: NICHOLS, Bill (org). Blurred Boundaries: questions of meaning in contemporary culture. Indianápolis: Indiana University Press, 1994. p. 92-107.

NICHOLS, Bill.Avoz do documentário. In: RAMOS, Fernão Pessoa(org.) Teoria contemporânea do cinema. v. 2. São Paulo: SENAC-SP, 2005. p. 47-67.

NICHOLS, Bill. Introdução ao documentário. Campinas, SP: Papirus, 2012.

OLIVEIRA, Leonardo Araújo. Filosofia e cinema em Deleuze: da imagem-movimento às condições de sua superação. In: Revista Pandora Brasil, n. 34, p. 1-13, set. 2011. Disponível em: $<$ http://revistapandorabrasil.com/revista_pandora/filosofia_34/leonardo.pdf $>$. Acesso em: 29 jan. 2018.

PEIRCE, Charles Sanders. Collected Papers of Charles Sanders Peirce. 8 volumes. Cambridge, Massachussets: The Belknap Press of Harvard University, 1978.

RAJCHMAN, John. O tempo em Deleuze ou como a cinemática muda nossa ideia de arte. In: PARENTE, André (Org.). Cinema/Deleuze. Campinas, SP: Papirus, 2013.

RAMOS, Fernão Pessoa. Mas afinal... o que é mesmo documentário? São Paulo: SENAC-SP, 2008.

RANCIÈRE, Jacques. De uma imagem à outra? Deleuze e as eras do cinema. In: RANCIÈRE, Jacques (Org). A fábula cinematográfica.. Campinas, SP: Papirus, 2003.

Recebido em: 07/02/2018

Aceito em: 28/11/2018 